Tropical Journal of Pharmaceutical Research July 2017; 16 (7): 1737-1746

ISSN: $1596-5996$ (print); 1596-9827 (electronic)

(C) Pharmacotherapy Group, Faculty of Pharmacy, University of Benin, Benin City, 300001 Nigeria.

All rights reserved.

Available online at http://www.tjpr.org

Review Article

http://dx.doi.org/10.4314/tjpr.v16i7.35

\title{
Therapeutic potentials and pharmacological properties of Moringa oleifera Lam in the treatment of diabetes mellitus and related complications
}

\author{
Elizabeth I Omodanisi ${ }^{1}$, Guillaume Y Aboua ${ }^{2}$ and Oluwafemi O Oguntibeju ${ }^{1 *}$ \\ ${ }^{1}$ Phytomedicine and Diabetes Research Group, Oxidative Stress Research Centre, Department of Biomedical Sciences, \\ ${ }^{2}$ Reproductive Biology Research Group, Faculty of Health and Wellness Sciences, Cape Peninsula University of Technology, \\ Bellville, South Africa. PO Box 1906, Bellville 7535, South Africa
}

*For correspondence: Email: oguntibejuo@cput.ac.za; bejufemi@yahoo.co.uk; Tel: +27711400428, +27219538495

Sent for review: 10 May 2016

Revised accepted: 13 June 2017

\begin{abstract}
Diabetes mellitus (DM) is a major health problem not only in urban areas, but also in rural areas. DM is a metabolic disorder resulting from abnormal insulin secretion. This leads to chronic hyperglycemia with disturbances of carbohydrate metabolism. Hyperglycemic-induced oxidative stress has been shown to be actively involved in the onset and progression of diabetes. Plants have played a vital role in improving the quality of life and maintaining human health.

It also serves as important components for medicines, beverages and seasonings. Many plants contain flavonoids, glycosides, alkaloids, terpenoids, and carotenoids with anti-diabetic and antioxidant properties. Moringa oleifera (MO) is one of such plants which have been used for centuries as a folk remedy for the treatment and management of various diseases including diabetes. This review is aimed at providing an overview of the potentials of $\mathrm{MO}$ in the treatment and management of diabetes and its possible applications in the treatment of other diseases.
\end{abstract}

Keywords: Moringa oleifera, Diabetes mellitus, Hyperglycemia, Oxidative stress.

Tropical Journal of Pharmaceutical Research is indexed by Science Citation Index (SciSearch), Scopus, International Pharmaceutical Abstract, Chemical Abstracts, Embase, Index Copernicus, EBSCO, African Index Medicus, JournalSeek, Journal Citation Reports/Science Edition, Directory of Open Access Journals (DOAJ), African Journal Online, Bioline International, Open-J-Gate and Pharmacy Abstracts

\section{INTRODUCTION}

Despite the presence of many methods, approaches and medicines, the management of type 2 diabetes mellitus remains unsatisfactory [1]. The increasing prevalence of diabetes in both developed and developing countries have challenged scientists to the discovery of various therapeutic agents that can be used to ensure efficient treatment and management of diabetes [2]. Also, with the increasing incidence of diabetes mellitus (DM) in rural population of Africa, many drugs have been formulated for the management of this chronic hyperglycemic disorder. However, there are limitations in the use of anti-hyperglycemic medications resulting from the side effects, high cost, limited action and secondary failure rates. There is a clear need for the development of indigenous, inexpensive herbal sources for diabetic treatment [3]. There is presently no cure for diabetes and the drugs available for the treatment and management of this disease are still unable to impair insulin deficiency. Less privileged diabetic patients are unable to purchase expensive drugs to manage this conditions or maintain their life style [4].

For several years, plants have been known to improve the quality of life and maintain human 
health. In addition, the components of plants have been used as seasonings, beverages, cosmetics, dyes, fertilizers and water purification. Interestingly, many indigenous plants containing flavonoids, glycosides, alkaloids, terpenoids, and carotenoids have been shown to contain both anti-diabetic and antioxidant properties. Moreover, Moringa oleifera (MO) has been found to be effective in ayurveda medicine; as a potent therapeutic agent with little or no adverse effect [5]. This review is aimed at providing an overview in the therapeutic potential and pharmacological properties of $\mathrm{MO}$ in the treatment and management of diabetes mellitus and other ailments.

The use of medicinal plants could be an alternative means of improving health care globally [6]. Medicinal plants are locally available, easily accessible and obtainable regardless of social status [7]. Concurrently, phytochemicals offer notable prospect for the exploration of new varieties of therapeutics. As a result, efforts are being geared globally towards the exploitation of medicinal plants containing phytochemicals to manage diabetes and associated complications [3].

DM remains a major global public health problem. It is a metabolic syndrome of multiple aetiologies characterized by chronic hyperglycemia resulting from defects in insulin, insulin actions or both. Hyperglycemia in DM has been associated with increased formation of reactive oxygen species (ROS) and inflammatory mediators. Consequently, if this metabolic syndrome is left untreated, it can lead to severe complications. Globally, increase in weight, obesity and sedentary lifestyle is gradually becoming prevalent resulting to diabetes. This may be due to a change of diet and lifestyle. Diabetes is projected to become the seventh leading cause of death worldwide by the year 2030 and total death from diabetes is estimated to rise by more than $50 \%$ in the next 10 years [ 8 , 9]. Many drugs have been designed for the treatment and management of this disease. However, there are limitations in the use of antihyperglycemic medications due to the side effects, high cost, limited actions and secondary failure rates [10]. There is increasing prevalence of diabetes in both developed and developing countries which have challenged scientists to further conduct research in sourcing for potent and affordable therapeutic agents from natural sources in the treatment and management of diabetes [6].

There are various evidences which indicate an increase in the generation of ROS and systemic markers of inflammation in both types of diabetes [11]. Increase in inflammatory cytokines such as IL-6, IL-18, IL-1 and TNF- $\alpha$ have been observed in the blood of patients with diabetes $[12,13]$. Chronic hyperglycemia and increased oxidative stress (disruption in the balance between the production of reactive molecules and antioxidant defenses) are the major factors in the development of secondary diabetic complications such as nephrotoxicity and hepatic injury [14-16].

\section{Possible risk factors of diabetes}

Oxidative stress, genetic factor, life style and environment are possible risk factors of diabetes. Diets have a significant role to play in the growth and development of the body [17]. Oxygen free radicals and other ROS are constantly produced in the human body. ROS are reactive species with partially reduced metabolites of oxygen. These metabolites initiate damaging effects to biomolecules which eventually lead to a change in the structure and function of these biomolecules. Studies have shown that type 2 diabetes is associated with increased oxidative damage to all biomolecules in the body [18]. Usually, the ROS are detoxified by antioxidant defense systems, although sometimes it reaches a point when there is an excess production of these ROS or inadequate antioxidant defense, which leads to oxidative damage. Increased oxidative stress is observed in diabetic patients as a result of free radical production [19]. Oxidative damage due to free radicals is associated with vascular disease in people with types 1 and 2 diabetes mellitus [20]. These factors have been implicated in the causative of several diseases in humans, such as diabetes, cancer, liver cirrhosis, atherosclerosis, neurodegenerative and cardiovascular diseases $[18,20]$. Individuals with type 1 diabetic parents have higher risk of inheriting diabetic genes. This can also be activated by other environmental factors and life style. In addition, physical inactivity is a risk factor of cardiovascular diseases, hypertension and dyslipidemia [18].

\section{DIABETES AND MORINGA OLEIFERA}

MO plant has been used in folklore medicine for the treatment of diabetes and other diseases [5]. Many indigenous plants such as Vernonia amygdalina (VA) [21], Garcinia kola [22], contain alkaloid, flavonoids, terpenoids, glycosides and carotenoids which have all been shown to contain anti-diabetic activities [23]. Ayurvedic medicine uses natural plants to promote selfhealing, attain good health and longevity. Researchers have indicated that Moringa oleifera can offer the nutrients and therapeutic 
ingredients to prevent, mitigate or treat many diseases or conditions [24]. This plant has been reported to possess antidiabetic, antioxidant and other medicinal properties which may be helpful in managing diabetes and its associated complications, and could possibly act as an effective remedy for the management of diabetes especially in low-income African communities [25-27].

$\mathrm{MO}$ is known in English by the names miracle tree, horseradish, drumstick, benzolive tree and named in respective native languages in other regions where it is grown. In Hindu, it is called Saijan, in Yoruba Ewe ile, in Filipino Mulanggay, in Hausa Zogale and in Igbo Odudu oyingbo [28, 29]. MO belongs to the family of Moringaceae, which is widely distributed in the tropics and subtropics of Asia and Africa [30]. The oleifera species has been in existence as far back as early 2000 BC, and is one of the world's most useful plants because of its medicinal properties [31]. MO has its origin in Agra and Oudh, in the northwest region of India, south of the Himalayan Mountains [32]. There are twelve (12) other known species: stenopetala which is a staple food of the indigenes of Ethiopia, pygmaea, peregrina (Forssk.), rivae, arborea, borziana, ruspoliana, longituba, concanensis, drouhardii, hilde- brandtii, and ovalifolia. Moringa oleifera shown in Figure 1 is the most researched among them [33-36].

\section{Uses of Moringa oleifera}

MO called miracle tree because every part of this plant is useful, has high nutritive value, and possesses numerous medicinal properties that can be used in treating or managing various diseases. $M O$ is a plant which can be eaten as a vegetable and used as beverages. A wide variety of nutritional and medicinal potentials have been attributed to its roots, bark, leaves, flowers, fruits, and seeds [31,37].

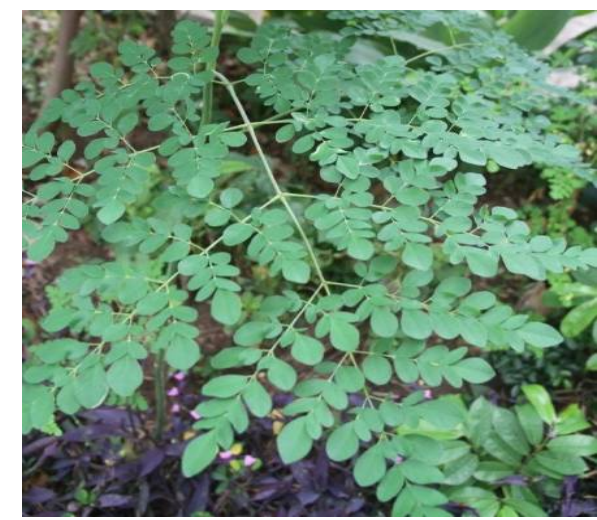

Figure 1: Moringa oleifera growing plant
Various parts of $\mathrm{MO}$ such as the leaves (Figure 2 ), roots, seeds (Figure 3\&4), bark, fruit, flowers and immature pods act as cardiac and circulatory stimulants, possess antitumor, antiulcer, antipyretic, antiepileptic activities [38]. In addition, $\mathrm{MO}$ has been used for the treatment and management of different ailments in traditional medicine because of the antihypertensive, antioxidant, antimicrobial, antibacterial, antispasmodic, antifungal, antiinflammatory, anti-tuberculosis, analgesic, antidiabetic, diuretic, cholesterol lowering, and hepatoprotective properties [31]. MO shows hypolipidaemic, antiatherosclerotic and immune boosting effects [39-41].

MO has been used for centuries as a folk remedy for stomach complaints, catarrh, cancer, gastric ulcers, skin diseases, lowering blood sugar, increasing bone density, nervous conditions, diabetes, fatigue, increase lactation, hay fever, impotence, oedema, cramps, hemorrhoids, headaches, sore gums; liver, gall, digestive, respiratory and immune system, as a blood cleanser, blood builder and wound healing $[42,43]$. The leaves of $\mathrm{MO}$ are anthelmintic aphrodisiac (increases sexual desire), cures hallucinations, dry tumors, hiccough and asthma [44]. $\mathrm{MO}$ is also used as stimulants, expectorant, and antilithic. Furthermore, it also provides a local solution to malnutrition [32]. $\mathrm{MO}$ is well known traditionally for the treatment of diabetes mellitus, hepatotoxicity, rheumatism, venomous bites and also for cardiac stimulation $[27,45,46]$.

Moringa oleifera is used in alley cropping (biomass production), biogas (from leaves), domestic cleaning agent (crushed leaves), animal forage (leaves and treated seed-cake), blue dye (wood), pulp (wood), fertilizer (seedcake), green manure (from leaves), gum (from tree trunks), medicine (all plant parts), honeyand sugar cane juice-clarifier (powdered seeds), honey (flower nectar), foliar nutrient (juice expressed from the leaves),

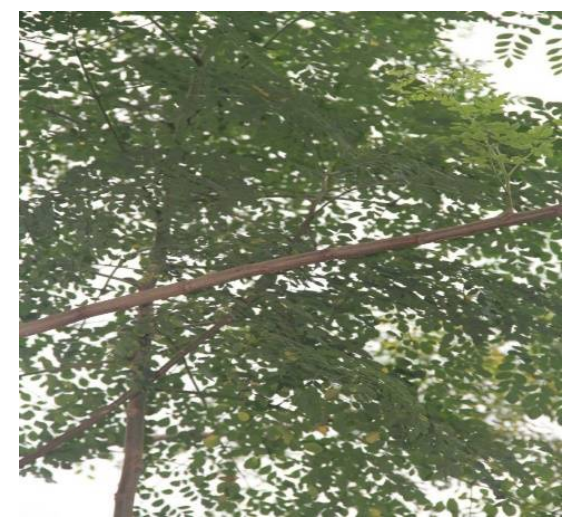

Figure 2: Moringa oleifera fresh leaf 
ornamental plantings, bio pesticide (soil incorporation of leaves to prevent seedling damping off), tannin for tanning hides (bark and gum), water purification (seeds) [29]. The oil extracted from MO seed known as Ben oil, is a sweet non-sticking and non-drying oil that resists rancidity [41].

People in many developing countries, especially in Africa have been using Moringa oleifera to treat and manage the symptoms of diabetes for years. The International Diabetic Federation (IDF), in a report stated that over 246 million people worldwide were suffering from the disease and the prevalence is expected to rise to 380 million by the year 2026 [6]. It is interesting to note that this plant can also grow in any type of soil and can be grown in the garden space at home. MO grows best in sandy or loamy soil with a slightly acidic $\mathrm{pH}$ and has a height ranging from 5 to $12 \mathrm{~m}$ with a straight trunk $10-30 \mathrm{~cm}$ thick [47].

\section{Constituents of Moringa oleifera}

The leaves of MO contain phytochemicals such as niazirin and niazirinin [44]. In addition, MO contains high level of vitamins $A, B$ and $C$ minerals (especially iron) amino acids (leucine, glutamic, valine, aspartic, alanine and so on), fatty acid, carotenoids (carotene, lutein xanthin, flavonoids, polyphenols (tannins), high in protein and antioxidants [31].

MO contains glucosinolates and flavonoids, anthocyanins, proanthocyanidin and cinnamates



Figure 3: Moringa oleifera seeds with husk<smiles></smiles>

Figure 5: Quercetin 3-(6"-malonyl-glucoside),
[33]. The leaves contain 4-( $\alpha$-Lrhamnopyranosyloxy) - benzylglucosinolate and three monoacetyl isomers of glucosinolate. Quantitative analysis carried out on the leaves revealed the presence of phenolic compounds quercetin 3-(6"-malonyl-glucoside) structure in Figure 5, quercetin-3-O-glucoside, and reduced concentration of kaempferol-3-O-glucoside (astragalin) with structure presented in Figure 6 and kaempferol-3-O-(6"-malonyl-glucoside), flavonoids and trace amount of alkaloid, 3caffeoylquinic and 5-caffeoylquinic acid $[30,44]$. Also, ethanolic and freeze dried leaves extract of $\mathrm{MO}$ has been reported to contain quercetin and kaempferol [48].

\section{Phytochemicals in Moringa oleifera}

Phytochemical studies on MO showed high polyphenols (kaempferol glycosides, rutin, quercetin glucosides, and chlorogenic acids) [49]. Some flavonol glycosides and benzoic acid 4-O-beta-glucoside, benzoic acid 4-O-alpharhamnosyl-(1 $\rightarrow 2)$-beta-glucoside and benzaldehyde 4-O-beta-glucoside have been isolated and characterized from methanolic extract of MO leaves [50]. Water soluble polysaccharides such as d-galactose, 6-O-Me-Dgalactose, D-galacturonic acid, I-arabinose, and I-rhamnose in a molar ratio of 1:1:1:1 were isolated from an aqueous extract of pods from Moringa oleifera [51]. Also, the seed of $\mathrm{MO}$ is reported to contain various sterols, tocopherols and fatty acids from n-hexane extract [37].

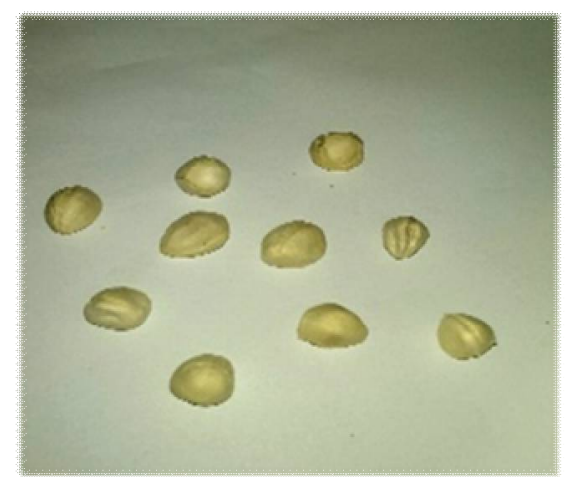

Figure 4: Moringa oleifera seeds without husk<smiles>O=c1c(OC2C(O)OC(CO)C(O)C(O)C2O)c(-c2ccc(O)cc2)oc2cc(O)cc(O)c12</smiles>

Figure 6: Kaempferol-3-O-glucoside 


\section{Therapeutic potentials of Moringa oleifera}

Currently available therapies for diabetes include insulin and various oral anti-diabetic agents such as sulfonylureas, biguanides, thiazolidine diones and glinides. Many of these drugs have some serious adverse effects. Therefore, there is a need to consider possible and safe hypoglycemic agents such as $\mathrm{MO}$ in the treatment and management of diabetes mellitus. A major mechanism in forestalling damage by oxidative stress is the balance of ROS and antioxidants, thus requiring the utilisation of dietary supplementation of antioxidant-rich plants such as MO which could be a promising approach in the treatment of diabetes [24]. Its beneficial effects in various pathological conditions through its anti-oxidative and anti-inflammatory properties have been researched on, hence the need to explore its potentials in diabetic conditions [24]. $\mathrm{MO}$ extract is reported to cause a reduction in the serum level of glucose and glycosylated protein in diabetic conditions while showing observable improvements in impaired glucose metabolism [31].

\section{Anti-diabetic activity of Moringa oleifera}

Several medicinal plants have been evaluated for their potential as beneficial agents in the treatment and management of diabetes. $\mathrm{MO}$ is also an important member of such plants. The leaves of $\mathrm{MO}$ was reported to significantly decrease blood glucose concentration in Wistar rats and Goto-Kakizaki (GK) rats, model type 2 diabetes [49]. Other studies also indicated MO's potency to effectively lower blood sugar levels $[52,53,54]$. The reduction in glucose concentration can be rationalized by the presence of potent polyphenols such as quercetin-3- glycoside, rutin and kaempferol glycosides in MO.

Studies undertaken in India to ascertain the hypoglycemic and anti-hyperglycemic outcome of $M O$ aqueous extract in normal (normoglycemic) and alloxan-induced diabetic rabbits respectively indicated that the aqueous extract of the leaves demonstrated hypoglycemic and antihyperglycemic activities [53]. Jaiswal et al. [55] examined the effect of the aqueous leaf extracts on glucose level, hemoglobin, total protein, urine sugar, urine protein and body weight of rats using three (3) different doses 100, 200 and 300 $\mathrm{mg} / \mathrm{kg}$. The results reveal that aqueous extract of $\mathrm{MO}$ leaf has significant hypoglycemic and antidiabetic potential [55].
Clinical studies were carried out to investigate the hypoglycemic effect of the seeds of Moringa oleifera $(\mathrm{MO})$ and Azadirachta indica (Al) seeds in 55 type 2 diabetic subjects (36 men and 19 women in the age group of 30-60 years). Results revealed that there was a significant reduction in the mean blood lipid levels. Among $\mathrm{MO}$ and $\mathrm{Al}$ seeds carefully chosen, MO seed powder was found to be more effective followed by Azadirachta indica seeds powder [56].

Studies on $\mathrm{MO}$ and other plants, investigated the hepato-protective properties using combined extracts of MO and VA in streptozotocin (STZ)induced diabetic using Wistar strain rats. It was observed that single and combined extracts of $\mathrm{MO}$ and VA have hepatoprotective effects and may be safer in preventing diabetes-induced damage to the liver [21]. Another study by Iwara et al [57] indicated that $\mathrm{MO}$ leaf extract combined with VA on STZ-induced diabetic rats was effective in reducing kidney damage. The result suggests a synergistic effect of the plants in the amelioration of nephrotoxicity associated with diabetes mellitus. Under this premise, one cannot conclude which particular plant extract has the potent active compound to treat and manage diabetes, therefore further and detailed studies are suggested [57].

Investigations were carried out on the effects of MO on glucose tolerance in Wistar rats and Goto-Kakizaki (GK) rats induced with diabetes with the knowledge that the major polyphenols in MO powder are quercetin glucosides, rutin, kaempferol, glycosides and chlorogenic acids [49]. The study indicated that $M O$ has an ameliorating effect for glucose intolerance, and the effect might be mediated by quercetin-3glucoside and fiber contents in MO leaf powder [49].

Studies carried out on MO view it as a very promising medicinal plant that can be used in the management and treatment of diabetes with minimal side effects. $\mathrm{MO}$ has also been shown to possess glucose lowering effect in STZ- induced diabetic rats by possibly stimulating the $\beta$-cells of the islets of Langerhans or due to its insulin-like activity [58].

\section{Anti-lipidaemic activity of Moringa oleifera}

MO leaves contain bioactive phytoconstituent, (beta-sitosterol) with cholesterol lowering effect. This compound is capable of reducing cholesterol level from the serum of high fat diet fed rats [38]. Mehta et al. [59] reported that the fruits of MO were reported to possess 
hypolipidaemic effect. They were found to lower the serum cholesterol, phospholipid, triglyceride, VLDL, LDL, cholesterol to phospholipid ratio and atherogenic index in hypercholesterolaemic rabbits, but were found to increase the HDL ratio (HDL/ HDL-total cholesterol) when compared with the control groups [59].

\section{Anti-inflammatory activity of Moringa oleifera}

The ethanolic extract of $\mathrm{MO}$ seeds was evaluated by Mahajan et al. [60] for its antiinflammatory activity against immune-mediated inflammatory responses in toluene diisocyanate (TDI) as antigen-induced asthma in Wistar rats. Similarly, another research was conducted in 2009 where anti-inflammatory activity of $\mathrm{MO}$ seeds (butanolic extract) against ovalbumininduced airway and inflammation in guinea pigs were evaluated [61]. Another study evaluated the antinociceptive and anti- inflammatory effects of the aqueous extract of the Moringa oleifera leaves, using the writhing, hot-plate and formalin tests as the antinociceptive assays, and carrageenan-induced paw oedema test as the anti-inflammatory assay. The extract (10, 30 and $100 \mathrm{mg} / \mathrm{kg})$ exhibited significant $(P<0.05)$ antinociceptive activity, which occurred in a dose-dependent manner in all tests used [61]. The extract also exhibited significant $(P<0.05)$ anti-inflammatory activity in a dose dependent manner. From the study, MO leaves were shown to possess anti-nociceptive and antiinflammatory activities which confirmed its traditional usage in the treatment of ailments, related to pain and inflammation [62].

\section{Antimicrobial activity of Moringa oleifera}

Antimicrobial activity of ethanolic extract of $\mathrm{MO}$ flowers, leaves and seeds was investigated. The study was carried out by Renita et al. [63] using micro-organisms; Escherichia coli, Salmonella typhi A Klebsiella pneumoniae, Candida albicans. Enterobacter spp, Pseudomonas aeroginosa, Proteus mirabilis and Staphylococcus aureus. The treatment with the leaves led to a significant reduction in the growth of these organisms. MO has the potency to combat microorganisms. The steam distillate was tested on fungal and bacterial by Kekuda et al. [64]. It was observed that the growth of fungi was inhibited by a decrease in colony diameter in plates poisoned with distillate compared to the control plates. Results from the study indicated more inhibition of $E$. coli compared to $S$. aureus, K. pneumoniae, $P$. aeruginosa and $B$. subtilis [64].

\section{Antioxidant activity of Moringa oleifera}

Antioxidants are chemicals derived from plants, vitamins and other nutrients which protect the cells of the body system from damage caused by free radicals; thus acting as free radical scavengers. Antioxidants are important in diabetes, they inhibit the oxidation of other molecules at low levels [65]. Reports on the antioxidant and free radical scavenging properties of methanol, ethanol and aqueous extracts of the dried leaves of $\mathrm{MO}$ have shown that the leaf extracts have free radical scavenging properties. Experimental study showed that methanol (80\%) and ethanol (70\%) were found as best solvents for the extraction of antioxidant compounds from $\mathrm{MO}$ leaves [66]. Also, protective effects of $\mathrm{MO}$ extract using 1,1diphenyl-2-picrylhydrazyl radicals (DPPH) and Trolox had IC (50) of 78.15+/-0.92 and 2.14+/$0.12 \mathrm{microg} / \mathrm{ml}$ respectively [39] has been reported.

\section{Anticancer activity of Moringa oleifera}

$\mathrm{MO}$ has been documented to contain anticancer properties. The extracts were tested using brine shrimp lethality assay and haemolysis assay to demonstrate the anticancer activity [67]. Cytotoxic effects were studied on human multiple myeloma cell lines using extracts of $\mathrm{MO}$ leaves and results showed the least viability at the highest dose [68].

\section{Hepato-protective activity of Moringa oleifera}

Hepato-protective action of $\mathrm{MO}$ against acetaminophen-induced liver injury in SpragueDawley rats have been reported using silymarin as a standard drug. The activity was a significant reduction of the level of alkaline phosphatase $(A L P)$, alanine aminotransferase $(A L T)$ and aspartate aminotransferase (AST) in groups pretreated with $\mathrm{MO}$ extract compared to those treated with acetaminophen alone. The level of glutathione (GSH) was found to be restored in MO treated animals compared to the groups treated with acetaminophen alone [69].

Hepato-protective effect of MO seed extract was evaluated on liver fibrosis, which was induced orally by administering $20 \%$ carbon tetrachloride $\left(\mathrm{CCL}_{4}\right)$ and Moringa oleifera seed extract $(1 \mathrm{~g} / \mathrm{kg} /$ day $)$ simultaneously. Liver fibrosis is the excessive accumulation of extracellular matrix proteins including collagen that occurs in most types of chronic liver diseases [70]. The $\mathrm{CCL}_{4}$ induced elevation of serum aminotransferase activities and globulin level was reduced as a 
result of the administration of $\mathrm{MO}$ seed extract. Treatment with $\mathrm{MO}$ also results in the reduction of the elevations of myeloperoxidase activity and hepatic hydroxyproline content [71].

\section{PREVENTION OF DIABETES}

Obesity is a serious chronic disease that may lead to type 2 diabetes and insulin resistance [71]. As a preventive measure against diabetes, engaging in regular exercise (aerobics, walking and jogging) will help maintain a normal growth and development, improve tissue sensitivity to insulin and keep the body physically fit. Eating healthy meals, fruits and fresh vegetables (including MO) will provide the needed nutrients for long-term weight maintenance. Physical activity also improves insulin sensitivity, glycemic control, and reduce selected risk factors for cardiovascular diseases (CVD) [17].

As a result of the numerous health benefits of this miracle plant, more studies to investigate its potential to treat and manage diabetes using an animal model in a more extensive study could potentially revolutionize natural products in the treatment and management of diabetes.

\section{CONCLUSION}

Diabetes mellitus is becoming a leading cause of death globally in both rural and urban areas. MO has been used in traditional medicine to treat diabetes and various diseases. Its pharmacological properties have drawn the interest of researchers to this plant. It can be used as an anti-diabetic, cholesterol lowering, anti-inflammatory, analgesic, hepatoprotective, anti-oxidant, anticancer, antiviral and wound healing agent. MO has shown beneficial effects in various pathological conditions in experimental animal models by acting as an anti-oxidative and anti-inflammatory agent through different mechanisms. The flowers, leaves, bark, and seeds of this plant are shown to possess active compounds that can help combat the issue of malnutrition, and to prevent and treat many disease conditions and promote good health. In view of the evidences of the potential effects of $\mathrm{MO}$ as revealed in previous studies, there is still the need for further studies to be done on the standardization of the extracts, and isolation of various active compounds present in the plant and their possible mode of action. Hence, more clinical trials should be carried out. Consequently, this will lead to its acceptance as a good therapy in the treatment and management of diabetes, thus potentially revolutionizing natural products in the treatment and management of diabetes.

\section{DECLARATIONS}

\section{Acknowledgement}

The authors would like to thank the Cape Peninsula University of Technology and the National Research Foundation (NRF) for the research fund granted to Professor $\mathrm{OO}$ Oguntibeju.

\section{Conflict of Interest}

No conflict of interest associated with this work.

\section{Contribution of Authors}

The authors declare that this work was done by the authors named in this article and all liabilities pertaining to claims relating to the content of this article will be borne by them.

\section{Open Access}

This is an Open Access article that uses a funding model which does not charge readers or their institutions for access and distributed under the terms of the Creative Commons Attribution License (http://creativecommons.org/licenses/by/ 4.0) and the Budapest Open Access Initiative (http://www.budapestopenaccessinitiative.org/rea d), which permit unrestricted use, distribution, and reproduction in any medium, provided the original work is properly credited.

\section{REFERENCES}

1. Singh $S N$, Vats $P$, Suri $S$, Shyam $R$, Kumria, MM, Ranganathan $S$, Sridharan $K$. Effect of an antidiabetic extract of Catharanthus roseus on enzymic activities in streptozotocin induced diabetic rats. J Ethnopharmacol 2001;76(3):269-277.

2. Gupta R, Mathur M, Bajaj VK, Katariya P, Yadav S, Kamal R, Gupta RS. Evaluation of antidiabetic and antioxidant activity of Moringa oleifera in experimental diabetes. J Diabetes 2012; 4(2): 164-171.

3. Atmakuri LR, Dathi S. Current trends in herbal medicines. J Pharm Res 2010;3(1):109-113.

4. Amod A, Ascott-Evans BH, Berg GI, Blom DJ, Brown SL, Carrihill MM, Dave JA, Distiller LA, Ganie YN The 2012 SEMDSA Guideline for the management of type 2 diabetes (Revised). J Endocrinol Metab Diabetes South Afri 2012;17(2):1-95.

5. Dièye AM, Sarr A, Diop SN, Ndiaye M, Sy GY, Diarra M, Faye $B$. Medicinal plants and the treatment of diabetes in Senegal: survey with patients. Fundam Clin Pharmacol 2008; 22(2): 211-216. 
6. Malviya $N$, Jain $S$, Malviya $S$. Review antidiabetic potential of medicinal plants. Drug Res $J$ 2010;67(2):113-118.

7. Maghrani M, Zeggwagh NA, Michel JB, Eddouks $M$. Antihypertensive effect of Lepidium sativum $L$. in spontaneously hypertensive rats. I Ethnopharmacol 2005;100(1-2):193-197.

8. Ansari NA, Dash D. Amadori Glycated Proteins: role in production of autoantibodies in diabetes mellitus and effect of inhibitors on non-enzymatic glycation. Age Dis 2013;4(1):50-56.

9. World Health Organization. Available from http://www. who.int/mediacentre/factsheets/fs312/en/. 2013

10. Baggio LL, Drucker DJ. Biology of incretins: GLP-1 and GIP. Gastroenterology 2007;132(2): 2131-2157.

11. Luqman S, Srivastava S, Kumar R, Maurya AK, Chanda $D$. Experimental Assessment of Moringa oleifera Leaf and Fruit for Its Antistress, Antioxidant, and Scavenging Potential Using In Vitro and In Vivo Assays. Evi Based Compl Altern Med 2012;2012:1-12.

12. Esposito K, Nappo F, Marfella R, Giugliano G, Giugliano $F$, Ciotola M. Inflammatory cytokine concentrations are acutely increased by hyperglycemia in humans: role of oxidative stress. Circulation 2002; 106:2067-2072.

13. Alexandraki KI, Piperi C, Ziakas PD, Apostolopoulos NV, Makrilakis $K$. Cytokine secretion in long standing diabetes mellitus type 1 and 2: association of low grade systemic inflammation. J Clin Immunol 2008; 28:3143121.

14. Huang C, Kim Y, Caramori ML, Fish AJ, Rich SS, Miller ME. Cellular basis of diabetic nephropathy: II. The transforming growth factor-beta system and diabetic nephropathy lesions in type 1 diabetes. Diabetes 2002; 51:3577-3581.

15. Kim JY, Lee SH, Song EH, Park YM, Lim JY, Kim DJ. A critical role of STAT1 in streptozotocin-induced diabetic liver injury in mice: controlled by ATF3. Cell Signal 2009;21:1758-1767.

16. Harrison $S A$. Liver disease in patients with diabetes mellitus. J Clin Gastroenterol 2006; 40:68-76.

17. American Diabetes Association, Standards of medical care in diabetes. Diabetes Care 2008;(31):12-54.

18. Veeranan V, Giridhari A, Malathi $D$, Geetha K. Antidiabetic property of drumstick (Moringa oleifera) leaf tablets. Int J Health Nutr 2011; 2(1):1-5.

19. Giugliano D, Ceriello A, Paolisso G. Oxidative stress and diabetic vascular complications. Diabetes Care 1996;19(3):257-267.

20. Oberley LW. Free radicals and diabetes. Free Radic Biol Med 1988; 5:113-124.

21. Efiong EE, Igile GO, Mgbeje BIA, Otu EA, Ebong PE. Hepatoprotective and anti-diabetic effect of combined extracts of Moringa oleifera and Vernonia amygdalina in streptozotocin-induced diabetic albino Wistar rats. Glob $J$ Hematol Endocr 2013;1(1):5-10.

22. Ayepola OR., Brooks NL, Oguntibeju OO. Kolaviron improved resistance to oxidative stress and inflammation in the blood (erythrocyte, serum, and plasma) of streptozotocin-induced diabetic rats. Sci World J 2014; 1-8.

23. Patel D, Prasad S, Kumar R, Hemalatha S. An overview on antidiabetic medicinal plants having insulin mimetic property. Asian Pac J Trop Biomed 2012; 2(4):320-330.

24. Singh $B N$, Singh $B R$, Singh $R L$, Prakash $D$, Dhakarey $R$, Upadhyay G, Singh HB. Oxidative DNA damage protective activity, antioxidant and anti-quorum sensing potentials of Moringa oleifera. Food Chem. Toxicol 2009;47(6):1109-1116.

25. Shanker K, Gupta M, Srivastava S, Bawankule D, Pal A, Khanuja SP. Determination of bioactive nitrile glycoside(s) in drumstick (Moringa oleifera) by reverse phase HPLC. Food Chem 2007;105(1):376-382.

26. Prod JN, Resour P, Mensah JK, Ikhajiagbe B, Edema NE, Emokhor J. Phytochemical, nutritional and antibacterial properties of dried leaf powder of Moringa oleifera (Lam) from Edo Central Province, Nigeria. J Nat Prod Plant Resour 2012;2(1):107-112.

27. Soliman GZA. Anti-diabetic activity of dried Moringa oleifera leaves in normal and streptozotocin (stz) induced diabetic male rats. Indian J Appl Res 2013;3(23):18-23.

28. Muhammad H, Soriani N. Evaluation of five Selected traditionally used medicinal plants for breast cancer treatment in Nigeria: A mini review. Online Int Interdiscip Res J 2014;4(3):16-27.

29. Fahey JW, Sc D. Moringa oleifera: A review of the medical evidence for Its nutritional, therapeutic and prophylactic properties. Trees life $J$ 2005;1(5):1-15.

30. Sreelatha S, Jeyachitra A, Padma PR. Antiproliferation and induction of apoptosis by Moringa oleifera leaf extract on human cancer cells. Food Chem Toxicol 2011;49(6):1270-1275.

31. Kumar PS, Mishra D, Ghosh G, Panda CS. Medicinal uses and pharmacological properties of Moringa oleifera. Int J Phytomedicine 2010;(2):210-216.

32. Mishra G, Singh P, Verma R, Kumar S, Srivastav $S$. Traditional uses, phytochemistry and pharmacological properties of Moringa oleifera plant: An overview. Der Pharm Lett 2011;3(2): 141-164.

33. Bennett, R. N., Mellon, F. A., Foidl, N., Pratt, J. H., Dupont, M. S., Perkins, L. Profiling glucosinolates and phenolics in vegetative and reproductive tissues of the multi-purpose trees Moringa oleifera L. (Horseradish Tree) and Moringa stenopetala L. J Agric Food Chem. 2003;51(12):3546-3553.

34. Spiliotis V, Lalas S, Gergis V. Comparison of antimicrobial activity of seeds of different Moringa oleifera varieties. Pharm Pharmacol Lett.1997;7(4):3940.

35. Steinitz B, Tabib Y, Gaba V, Gefen T, Vaknin $Y$. Vegetative micro-cloning to sustain biodiversity of threatened Moringa species. Vitr Cell Dev Biol. 2008;45(1):65-71.

36. Sánchez NR, Ledin S, Ledin I. Biomass production and chemical composition of Moringa oleifera under different 
management regimes in Nicaragua. Agrofor Syst. 2006, 66(3):231-42.

37. Anwar F, Latif S, Ashraf M, Gilani AH. Moringa oleifera: a food plant with multiple medicinal uses. Phytother Res. 2007; 21(1):17-25.

38. Farooq F, Rai M, Tiwari A, Khan AA, Farooq S. Medicinal properties of Moringa oleifera: An overview of promising healer. J. Med. plants Res. 2012; 6(27):4368-4374.

39. Chumark $P$, Khunawat $P$, Sanvarinda $Y$, Phornchirasilp $S$, Morales NP, Phivthong-ngam $L$. The in vitro and ex vivo antioxidant properties, hypolipidaemic and antiatherosclerotic activities of water extract of Moringa oleifera Lam. leaves. J Ethnopharmacol. 2008;116, (3): $439-446$

40. lqbal S, Bhanger MI. Effect of season and production location on antioxidant activity of Moringa oleifera leaves grown in Pakistan. J Food Compos. Anal. 2006;19:544551.

41. Faizi S, Siddiqui BS, Saleem R, Siddiqui S, Aftab K, Gilani $A H$. Isolation and structure elucidation of new nitrile and mustard oil glycosides from Moringa oleifera and their effect on blood pressure. J. Nat. Prod. 1994; 57(9):1256-1261.

42. Mehta J, Shukla A, Bukhariya V, Charde R, Road R. The magic remedy of Moringa oleifera: An overview. Int $J$ Biomed Adv Res. 2011;2(6):1-13.

43. Rathi BS, Bodhankar SL, Baheti AM. Evaluation of aqueous leaves extract of Moringa oleifera Linn for wound healing in albino rats. Indian J Exp Biol. 2006; 44(11):898-901.

44. Goyal BR, Agrawal BB, Goyal RK, Mehta AA. Phytopharmacology of Moringa oleifera Lam. ó An overview. Nat Prod Radiance. 2007; 6(4):347-353.

45. Babu R, Chaudhuri M. Home water treatment by direct filtration with natural Coagulant. J Water Health. 2005:3.27-30.

46. Ruckmani K, Kavimani S, Ananda R, Jaykar B. Effect of Moringa oleifera Lam. on paracetomol induced hepatotoxicity. Indian J Pharm Sci. 1998; 60:33-35.

47. Hussain S, Malik, F, Mahmood S. An exposition of medicinal preponderance of Moringa oleifera (Lank.) Pak J Pharm Sci. 2014;27(2):397-403.

48. Siddhuraju P, Becker K. Antioxidant properties of various solvent extracts of total phenolic constituents from three different agroclimatic origins of drumstick tree (Moringa oleifera Lam.) leaves. J Agric Food Chem. 2003; 51(8):2144-2155.

49. Ndong M, Uehara M, Katsumata SI, Suzuki K. Effects of oral administration of Moringa oleifera Lam on glucose tolerance in Goto-Kakizaki and Wistar rats. J Clin Biochem Nutr. 2007; 40(3):229-233.

50. Manguro LO, Lemmen P. Phenolics of Moringa oleifera leaves. Nat Prod Res. 2007;21(1): 56-68.

51. Roy SK, Chandra K, Ghosh K, Mondal S, Maiti D, Ojha AK, Das D, Mondal S, Chakraborty I, Islam SS. Structural investigation of a heteropolysaccharide isolated from the pods (fruits) of Moringa oleifera (Sajina). Carbohydr Res. 2007; 342(16):2380-2389.
52. Edoga CO, Njoku OO, Amadi EN, Okeke JJ. Blood sugar lowering effect of Moringa oleifera Lam in albino rats. Int J Sci Technol. 2013;3(1)88-90.

53. Manohar VS, Jayasree T, Kishore KK, Rupa LM, Dixit R. Research article evaluation of hypoglycemic and antihyperglycemic effect of freshly prepared aqueous extract of Moringa oleifera leaves in normal and diabetic rabbits. J Chem Pharm Res. 2012; 4(1) 249-253.

54. Fahim M, Shahdaat M, Sayeed B, Shams T, Mia MMK. Ethnobotanical survey of medicinal plants used by Bangladeshi traditional health practitioners in the management of diabetes mellitus. J Ethnopharmacol. 2012; 144(3): 605-611.

55. Jaiswal D, Rai PK, Kumar A, Mehta S, Watal G. Effect of Moringa oleifera Lam. leaves aqueous extract therapy on hyperglycemic rats. J Ethnopharmacol. 2009; 123:392-396.

56. Kumari DJ. Hpoglycaemic effects of Moringa oleifera and Azadirachta Indica in type 2 diabetes mellitus. The Bioscan. 2010;5(2):211-214.

57. Iwara IA, Otu EA, Effiong E, Igile GO, Mgbeje B, Ebong $P$. Evaluation of the nephroprotective effects of combined extracts of Vernonia amygdalina and Moringa oleifera in diabetes induced kidney injury in albino Wistar rats. Sch J App/ Med Sci. 2013; 1(6): 881-886.

58. Tende JA, Ezekiel I, Dikko AAU, Goji ADT. Effect of ethanolic extract of Moringa oleifera on blood glucose levels of streptozotocin - induced diabetics and normoglycemic rats. Br J Pharmacol. 2011;2(1):1-4.

59. Mehta K, Balaraman R, Amin AH, Bafna PA. Gulati $O D$. Effect of fruits of Moringa oleifera on the lipid profile of normal and hypercholesterolaemic rabbits. $J$ Ethnopharmacol. 2003; 86(2): 191-195.

60. Mahajan SG, Mali RG, Mehta AA. Effect of Moringa oleifera Lam. seed extract on toluene diisocyanateinduced immune-mediated inflammatory responses in rats. J Immunotoxicol. 2007; 4(2): 85-96.

61. Mahajan SG, Banerjee A, Chauhan BF, Padh $H$, Nivsarkar M, Mehta AA. Inhibitory effect of n-butanol fraction of Moringa oleifera Lam. Seeds on ovalalbumininduced airway inflammation in guinea pig model of asthma. Int J Toxicol. 2009;28;(6):519-527.

62. Sulaiman MR, Zakaria ZA, Bujarimin AS, Somchit MN, Israf DA, Moin S. Evaluation of Moringa oleifera aqueous extract for antinociceptive and antiInflammatory activities in animal models. Int $J$ Pharm Sci Res. 2008; 46(12):838-845.

63. Renita RE, Anitha J, Napolean P. Isolation, analysis and identification of phytochemicals of antimicrobial activity of Moringa oleifera Lam. Current Biotica. 2009; 3(1):3337.

64. Kekuda TRP Mallikarjun N, Swathi D, Nayana KV, Aiyar $M B$, Rohini TR. Antibacterial and antifungal efficacy of steam distillate of Moringa oleifera Lam. J Pharm Sci Res. 2010; 2(1):34-37.

65. McCune LM, Johns T. Antioxidant activity in medicinal plants associated with the symptoms of diabetes mellitus used by the Indigenous peoples of the North 
American boreal forest. J Ethnopharmacol 2002; 82(23):197-205.

66. Sreelatha S, Padma PR. Antioxidant activity and total phenolic content of Moringa oleifera leaves in two stages of maturity plant foods. Hum Nutr. 2009;64(4):303-311.

67. Costa-Lotufo LV, Khan MT, Ather A, Wilke DV, Jimenez PC, Pessoa C, de Moraes ME, de Moraes MO. Studies of the anticancer potential of plants used in Bangladeshi folk medicine. J Ethnopharmacol. 2005; 99:(1):21-30.

68. Parvathy MVS, Umamaheshwari A. Cytotoxic effects of Moringa oleifera leaf extracts on human multiple myeloma cell lines. Trends Med Res. 2007; 2(1):44-50.

69. Fakurazi S, Nanthini U, Hairuszah I. Hepatoprotective and antioxidant action of Moringa oleifera Lam. against acetaminophen induced hepatotoxicity in rats. Int $J$ Pharmacol. 2008;4(4) 270-275.

70. Bataller R, Brenner DA. Liver fibrosis. J Clin Invest. 2005;115(2):209-218.
71. Hamza AA. Ameliorative effects of Moringa oleifera Lam seed extract on liver fibrosis in rats, Food Chem Toxicol. 2010;48:(1):345-355.

72. Ara NM. Rashid, Amran MS. Comparison of Moringa oleifera leaves extract with Atenolol on serum triglyceride, serum cholesterol, blood glucose, heart weight, body weight in adrenaline induced rats, Saudi $J$ Biol Sci. 2008;15(2):253-258.

73. Rathi BS, Bodhankar SL, Baheti AM. Evaluation of aqueous leaves extract of Moringa oleifera Linn for wound healing in albino rats. Indian $J$ Exp Biol. 2006;44(11):898-901.

74. Kinfe HH, Belay YH, Joseph JS, Mukwevho E. Evaluation of the influence of thiosemicarbazone-triazole hybrids on genes implicated in lipid oxidation and accumulation as potential anti-obesity agents. Bioorg Med Chem Lett. 2013;23(19):5275-5280. 